\title{
Anthropogenic Impacts on Biochemical Processes in a Tropical Estuarine Lagoon
}

\author{
"Hong Le Vu, Ron Johnstone \\ School of Earth and Environmental Sciences, the University of Queensland, Australia \\ "Email: h.vu2@uq.edu.au
}

\begin{abstract}
Estuaries play an invaluable role in the transformation and cycling of materials as they move between land and sea; including anthropogenic materials. Increasingly, human land use is delivering material loads that risk overwhelming the normal functions that these ecosystems provide. In this context, the objective of this study is to assess key biogeochemical processes to understand the connections of anthropogenic activities on ecosystem performance in a tropical estuarine lagoon system. This research focuses on a case study area, Dong Ho lagoon in Vietnam, which exemplifies the anthropogenic impacts and management issues facing most of the Mekong coastline and other similar areas in Vietnam. Located at the south-western edge of the Mekong delta, the Dong Ho estuary is subject to material inputs from both local and more remote sources; making it vulnerable to degradation and functional loss. This paper summarises the key findings from an assessment of the Dong Ho estuarine functions and highlights potential risks it is currently facing.
\end{abstract}

Indexed Terms- Biogeochemical processes; Tropical estuary

\section{INTRODUCTION}

Dong Ho estuarine lagoon is located in the Kien Giang biosphere reserve and is part of the Southern Mekong delta of Vietnam. Dong Ho lagoon is the central area of Dong Ho estuary and is connected to Southwest sea through the To Chau channel. Dong Ho estuary has a long history of landscape changes and represents an important cultural heritage area of the Mekong delta and Vietnam. Since the 1990's, Dong Ho estuary and its surrounds have been significantly altered due to the influences of human activities [1]. Perhaps one of the most profound alterations to the Dong Ho estuary system came with the implementation of flood drainage system to the West sea under the national government flood management policy in 1997 [1]. One of the major outcomes of this strategy is the increased flows from the Hau River via Vinh Te canal and Giang Thanh River into the Dong Ho estuary. This has significantly increased flows and material inputs into Dong Ho during the wet season [1-2]. In addition, Rach Gia - Ha Tien canal in the southeast of Dong Ho also contributes substantial freshwater inputs from Long Xuyen Quadrangle as well as high sedimentation rates into the lagoon.

In addition to this change in flows, these have also been significant changes in land use within the catchment feeding the Dong Ho ecosystem [2]. The step changes from low intensity farming to intense rice production along the Vinh Te canal and the associated areas since 2005 typifies the extent and intensity of changes that are occurring in the Dong Ho system [2]. Moreover, the establishment of the sea dyke in 2003 to build the commercial area of Ha Tien town and the ensuing land reclamation in 2005 in the west sea off Ha Tien have also strongly affected the coastal line of Ha Tien, including the hydrological characteristics of Dong Ho so that water flows from the lagoon to the open sea are more constrained [2]. Furthermore, since 2011, land reclamation to the east of Dong Ho for new residential areas has further exacerbated this situation [2]. Although there have been no empirical studies to date, there is strong anecdotal evidence that these changes have strongly influenced the Dong Ho ecosystem. 
One other aspect that has changed in the Dong Ho area is the distribution and abundance of wetland forests which have been increasingly replaced with nipa palm and aquaculture activities. Almost $50 \%$ of the lagoon surrounds have been converted to these uses in the last 10 years. This issue is considered as one of the most threatening factors for water quality and biological function of Dong Ho lagoon. In addition, the development of urban areas, including the increase of population and immigration to Ha Tien town and To Chau due to tourism development in the upcoming years will further alter the land use around Dong Ho and potentially exacerbate existing problems of pollution and nutrient cycling throughout the ecosystem.

\section{METHODS}

Based on the insights and knowledge about its hydrological, bathymetric conditions, biophysical features, and nutrient stocks in waters and sediments, Dong Ho estuarine lagoon was divided into three main zones (Figure 1.1) and sediment cores were randomly collected from each zone for process measurements. The first zone is the deepest area where all the water exchange between the lagoon and the open sea. The second zone is the central lagoon and the third one is the shallowest area in the northeast of lagoon. To reflect the influences of different seasons on nutrient processes and metabolism of the ecosystem, the sediment cores were collected and incubated in-situ in both dry season and wet season.

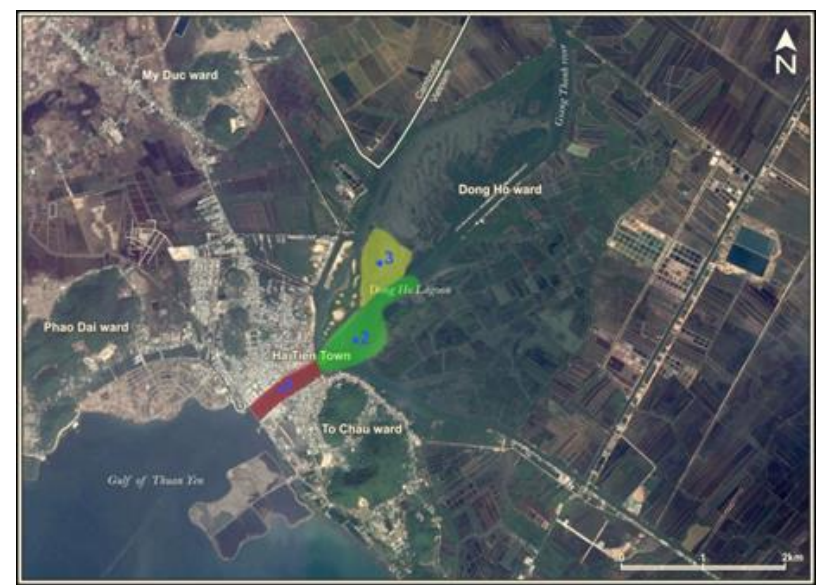

Figure 1: Location of 3 main zones in Dong Ho lagoon

In this research, measurements of biogeochemical processes focus on identifying the rate of primary production, benthic nutrient fluxes and denitrification in Dong Ho estuarine lagoon. Primary production and nutrient flux assessment are calculated based on the rate changes of dissolved oxygen and nutrient concentrations respectively in the water overlying the sediment core samples [3-6]. The ${ }^{15} \mathrm{~N}$ isotope pairing technique was used to measure the denitrification rate in Dong Ho lagoon because this method can identify both nitrate diffusing from the overlying water column as well as nitrate produced from the nitrification process within the sediment [7].

\section{RESULTS AND DISCUSSIONS}

Primary production and respiration rates varied between wet and dry seasons (Figure 1.2). In particular, dry season results showed strange heterotrophy than in the wet season with higher rates of respiration in all sampling sites. Gross primary production in the dry season was also higher in wet season. Also there were larger differences between GPP of the three zones in the dry season while in the wet season GPP was quite similar between sampling sites. Mean GPP of whole system in wet 
season was $45.5 \pm 2.3 \mathrm{mmolC} / \mathrm{m}^{2} /$ day while in dry season GPP of whole system varied from 19 to 178 $\mathrm{mmolC} / \mathrm{m}^{2} /$ day with the highest rate is from zone 1 and the lowest rate is from zone 2 .

Based on calculations, it was showed that Dong Ho lagoon is a net heterotrophic system due to the net ecosystem production (NEP) is negative and $\mathrm{P} / \mathrm{R}$ is $<1$. One of the main reasons that can be explained through physical and biological parameters of water column is due to light limitation by turbidity of primary production. DO in all sediment cores decreased during light incubations indicating that the rate of respiration in the cores exceeds GPP. This is likely due to high levels of organic matter and heterotrophic activity in the sediment core. Negative NEP also indicates a significant amount of carbon is being respired in Dong Ho lagoon.

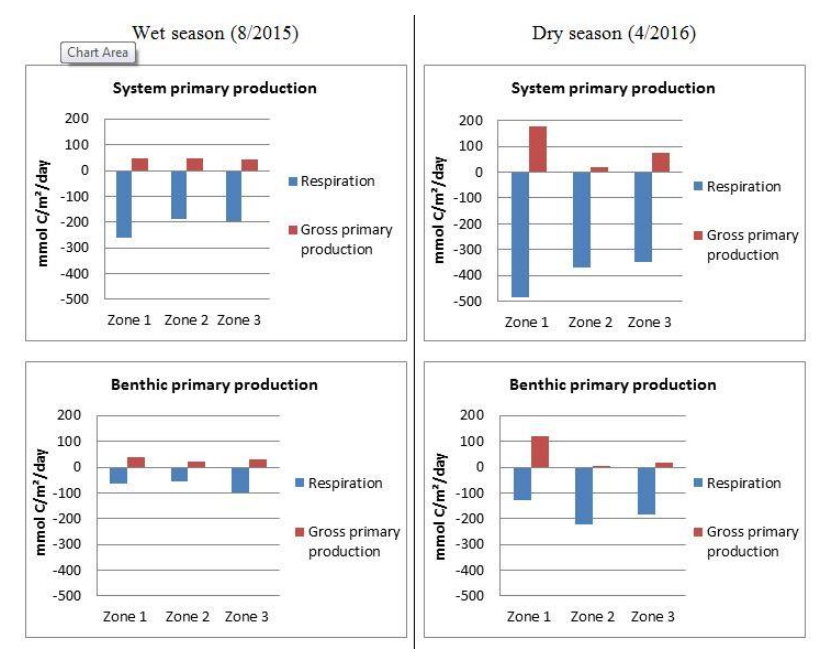

Figure 2: Primary production \& respiration rates in Dong Ho lagoon

A comparison with other estuarine and marine studies suggests that the benthic nutrient flux rates in Dong Ho lagoon were in the highest range in wet season and in the normal range in dry season [4][8-9]. In wet season, NOx flux in all sampling sites showed an uptake in both dark and light incubation. It suggested that denitrification process was potential in Dong Ho lagoon. However, nutrient fluxes were highly variable between zones and seasons. It may lead to the differences in denitrification and nitrification rates across the lagoon and between dry and wet season.

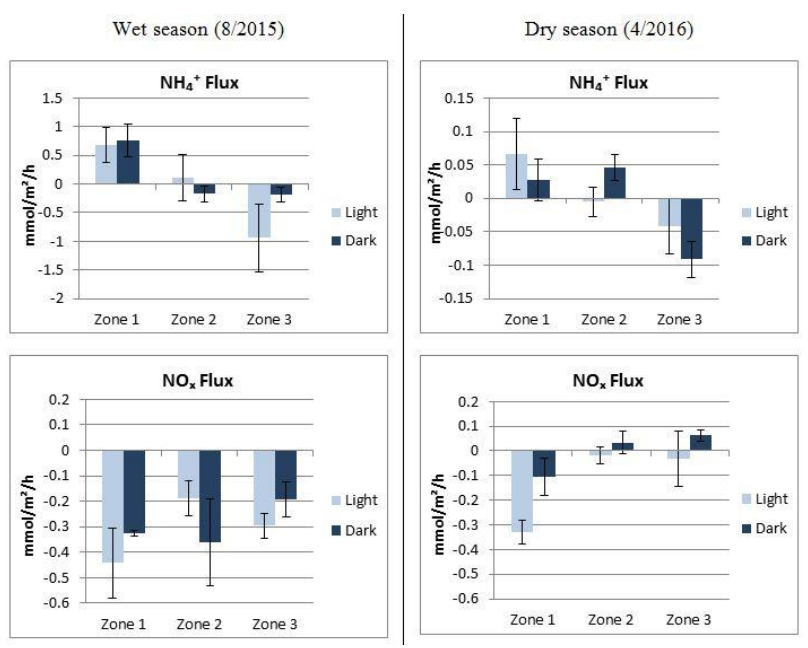

Figure 1.3: Benthic nutrient fluxes in Dong Ho lagoon

The average values of benthic fluxes of $\mathrm{NH}_{4}{ }^{+}$and $\mathrm{NO}_{\mathrm{x}}$ in light and dark incubations in both seasons in Dong Ho lagoon was illustrated in figure 1.3. Error bars are the standard deviation of three 
replicate cores. Positive value of fluxes represents sediment release nutrients and negative value indicates sediment uptake.

In wet season, $\mathrm{NH}_{4}{ }^{+}, \mathrm{NO}_{\mathrm{x}}$ fluxes in Dong Ho lagoon were similar to other estuaries and coastal lagoons where are heavily impacted by anthropogenic activities [4][9-10]. However, $\mathrm{PO}_{4}{ }^{3-}$ fluxes in Dong Ho lagoon was lower compared to those systems. Sediments in Dong Ho lagoon generally showed a released of $\mathrm{PO}_{4}{ }^{3-}$, except zone 1 in wet season. $\mathrm{PO}_{4}{ }^{3-}$ efflux often accompanies reduced DO concentrations and with the duration of hypoxic conditions in sediments [11-12]. This statement is perfectly correct in the case of Dong Ho lagoon because the $\mathrm{PO}_{4}{ }^{3-}$ efflux was happened in all sampling sites in dry season and matched with a period of lower DO in the bottom water (around $3-4 \mathrm{mg} / \mathrm{l})$. In addition, low oxygen concentration and high temperature in sediments may enhance the release of $\mathrm{P}$ to water column [10].

The denitrification rates measured in this study are at the higher end of the range previously recorded in other coastal and estuarine sediments in both tropical, sub-tropical and temperate systems [10]. The average measures of net $\mathrm{N}_{2}$ production calculated in Dong Ho lagoon range from $400-$ $1000 \mu \mathrm{mol} \mathrm{N} \mathrm{N}_{2}-\mathrm{Nm}^{-}{ }^{2} \mathrm{~h}^{-}{ }^{1}$. Despite the relatively high rates, denitrification may not play a significant role in the sediment of Dong Ho lagoon if compared with potential nitrification, anammox or dissimilatory nitrate reduction to ammonium (DNRA) process. For example, in zone 1 at both seasons, DNRA process was likely dominated in sediments. In tropical and subtropical coastal systems, due to high organic matter content, oxygen deficit, sulfate reduction and high temperature, DNRA is predominated over denitrification and it was demonstrated by many studies [10].

\section{CONCLUSIONS}

Dong Ho lagoon receives various input sources from nature processes and human activities. A lot of materials draining from land to Dong Ho lagoon in order to discharge to sea. Nutrient loads can be derived from diffuse sources or point sources. In the case of Dong Ho lagoon, the majority of carbon and nutrient inputs occur from the land uses in the immediate surrounds, although, in view of the interconnected canal systems, there is potential for materials to also be drawn from more remote areas. Shrimp and rice farming production cycle in the catchment of Dong Ho lagoon and Mekong Delta affects the nutrient release to the lagoon. Although nutrient standing stocks were abundant, Dong Ho estuarine lagoon has lower primary production compared to other estuaries due to high respiration rate in water column and in benthos, especially in dry season respiration rate is very high. Primary production in Dong Ho estuarine lagoon is light limited due to high turbidity, and driving this system toward heterotrophy.

Estuaries have a capacity to assimilate certain levels of anthropogenic pollutants without a significant loss of ecosystem services. However, in many estuaries or some segments of them, human activities exceeded this capacity and they suffered persistent ecological damage from estuary to estuary, and also from segment to segment within an estuary as well (Schubel, 1975). The synthesis knowledge about how theses biogeochemical processes control ecosystem assimilative capacity is particularly significant to management strategies for estuarine systems receiving extensive human impacts like Dong Ho lagoon.

\section{REFERENCES}

[1] Nguyen, N. T. 2011. Analyzing changes in Dong Ho lagoon in recent decades. In: R. W. Carter, A. V. C. C. (ed.) Integrated planning for conservation and development of Dong Ho Lagoon, Vietnam, Ha Tien, 10-11 November, 2011. . Rach Gia, Vietnam: Deutsche Gesellschaft für Internationale Zusammenarbeit (GIZ), Conservation and Development of the Kien Giang Biosphere Reserve Project.

[2] Carter, R. W. 2012. Guidelines for integrated planning for conservation and development of Dong Ho lagoon Viet Nam. In: CHU, V. C. \& BROWN, S. (eds.) Report of the Australian 
AID-GIZ Conservation and Development of the Kien Giang Biosphere Reserve Project, GIZ, Rach Gia, Viet Nam.

[3] Kemp, W. M. \& Boynton, W. R. 1980. Influence of biological and physical processes on dissolved oxygen dynamics in an estuarine system: Implications for measurement of community metabolism. Estuarine and Coastal Marine Science, 11, 407-431.

[4] Jenkins, C. H. 2005. Nutrient flux assessment in the Port waterways.

[5] Seeley, C. 1969. The diurnal curve in estimates of primary productivity. Chesapeake Science, $10,322-326$

[6] Odum, H. T. 1956. Primary Production in Flowing Waters1. Limnology and Oceanography, $1,102-117$.

[7] Nielsen, L. P. 1992. Denitrification in sediment determined from nitrogen isotope pairing. FEMS Microbiology Letters, 86, 357-362

[8] Hanington, P., Rose, A. \& Johnstone, R. 2016. The potential of benthic iron and phosphorus fluxes to support the growth of a bloom forming toxic cyanobacterium Lyngbya majuscula, Moreton Bay, Australia. Marine and Freshwater Research, -.

[9] Burford, M., Alongi, D., mckinnon, A. \& trott, L. 2008. Primary production and nutrients in a tropical macrotidal estuary, Darwin Harbour, Australia. Estuarine, Coastal and Shelf Science, 79, 440-448.

[10] Pérez-Villalona, H., Cornwell, J. C., Ortiz-Zayas, J. R. \& Cuevas, E. 2015. Sediment Denitrification and Nutrient Fluxes in the San José Lagoon, a Tropical Lagoon in the Highly Urbanized San Juan Bay Estuary, Puerto Rico. Estuaries and Coasts, 38, 2259-2278.

[11] Didonato, G. T., Lores, E. M., Murrell, M. C., Smith, L. M. \& Caffrey, J. M. 2006. Benthic Nutrient Flux in a Small Estuary in Northwestern Florida (USA). Gulf and Caribbean Research, 18.

[12] Cowan, J. L. W. \& Boynton, W. R. 1996. Sediment-water oxygen and nutrient exchanges along the longitudinal axis of Chesapeake Bay: Seasonal patterns, controlling factors and ecological significance. Estuaries, 19, 562-580. 